\title{
In search of dry powder
}

\author{
Jonathan Behr \& Phil Murray \\ Which investment firms are currently actively investing in new biomedical startups?
}

\begin{abstract}
Bioten iotech entrepreneurs face a slew of challenges-from honing their company's development plan and strategy to aligning the right team and collaborators. When the time comes to raise money, the financing process itself can seem a daunting and time-consuming hurdle. If you have already found money from angels, family and friends, you will need to move to the next level of financing. This may mean pitching to venture capitalistswho may fund fewer than $1 \%$ of the deals they review (J.S. Petty and M. Gruber, J. Bus. Venturing 26, 172-188, 2011) but also can take up weeks or months of your time before they make an investment decision, a time commitment that is multiplied by the number of firms you pitch.
\end{abstract}

As an institutional/serial entrepreneur (Box 1), our firm, PureTech (Boston, MA), actively interacts with the venture capital (VC) community and has a broad network useful in gathering intelligence on VC firms. Even for us, discerning which VC funds are actively seeking to invest in new opportunities is a challenge. This is because so many factors are involved in these decisions: for example, a firm could have several billion dollars under management but actually have limited or no remaining funds allocated for companies outside of its existing portfolio. Furthermore, some firms can be opaque about their ability to make a new investment, and their threshold for doing so, to protect their ability to operate and fundraise.

Thus, to move more efficiently through the VC fundraising process, you should

Jonathan Behr is a principal at PureTech and Vice President of New Ventures at Enlight Biosciences, Boston, Massachusetts, USA. Phil Murray is an associate at PureTech, Boston, Massachusetts, USA.

e-mail:jbehr@enlightbio.comor pmurray@puretechventures.com

\section{Box 1 PureTech and Enlight}

PureTech considers itself a technology development company. We partner with industry and scientist-inventors to create new companies by first deconstructing problems and then seeking to solve them in entirely new ways. We concentrate on a handful of major initiative areas at a time, generate and review hundreds of technologies, and drive forward one or two programs a year.

In 2008, PureTech launched Enlight Biosciences (Cambridge, MA), an entrepreneurial partnership alongside seven major pharmaceutical companies. Enlight leverages PureTech's model with a focus on developing the next generation of transformational platform technologies. Together, PureTech and Enlight have developed a pipeline of more than a dozen products, including several clinical-stage programs. avoid pitching to (or jumping through diligence hoops for) funds that are unlikely to invest and instead prioritize those that are a good fit. To identify these, we recommend using both public data and word of mouth. To aid entrepreneurs, last year we created a blog post (http://bit.ly/15KLHFm) linked to a living document, containing assessments of various funds, that relies both on traditional information sources (past investments, fund size, vintage year) and on input from the 'crowd' of venture capitalists and entrepreneurs, to improve accuracy. Here, we expand on that blog post, focusing on the tools you can use to prioritize VC funds to approach and discussing when these tools apply to traditional fund-structured (Box 2) or nontraditional VC funds (Box 3). Although the information provided is accurate to the best of our abilities, by its nature this analysis is incomplete, and omitted funds may in fact be actively investing in new early-stage opportunities. We encourage readers to contribute to updating and correcting this dataset using the mechanisms described in Box 4.

\section{A fund's life cycle}

It is important for entrepreneurs to consider not only a VC fund's interest in their company's specific niche but also the fund's life cycle stage-critical to predicting future investment activity. The term 'dry powder' is

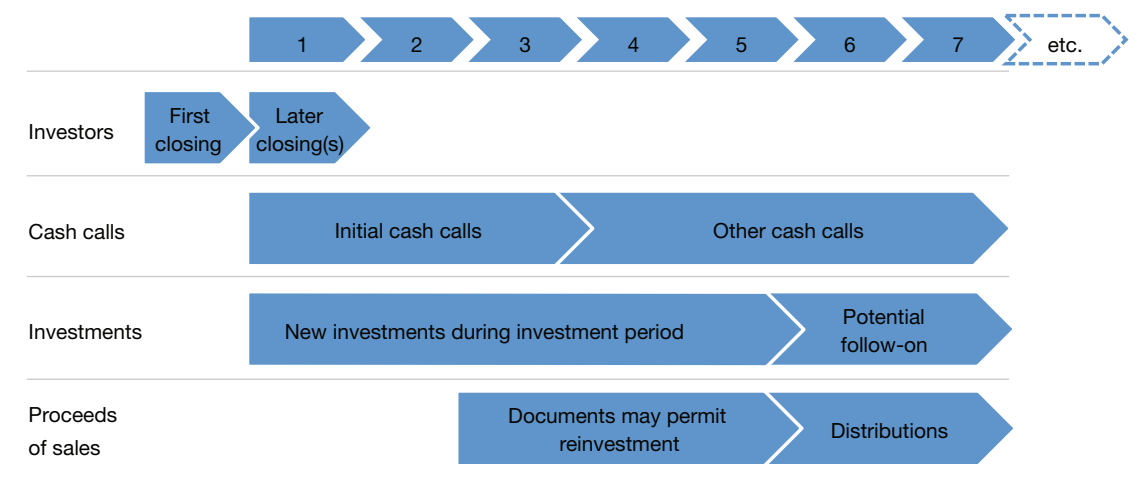

Figure 1 Life cycle of a sample VC fund. 


\section{Box 2 Traditional venture capital-the basics}

Traditional VC funds are usually raised with a specific investment thesis or focus, which may limit which opportunities a firm will consider. In many cases, funds will designate a sector-specific focus (such as life sciences, health IT or therapeutics) and invest exclusively in corresponding opportunities.

Using Abingworth as an example, its website (http://www. abingworth.com/) says it invests in "life sciences and healthcare," including "platform and enabling technologies, medical devices, instrumentation, companies developing therapeutics and healthcare services businesses." Abingworth invests in early- and late-stage venture, growth equity and public markets primarily in the United States, UK and Europe. Although these descriptions are helpful, they may not reflect what the firm is actually interested in today on the basis of projected new investment performance, recent successes and failures, and feedback from their own general or limited partners.

Unlike Abingworth, funds may elect to focus on a more particular stage of investment, though they might also use other criteria like geography or the availability of co-investors. The website of Arboretum Ventures, for example, says that the firm invests "throughout the United States, but with a special interest in the
Midwest." A firm's investment strategy may also dictate whether it is willing to 'lead' an investment round (that is, serve as the first and usually largest investor, responsible for the negotiation of the terms and usually the brunt of the diligence), which generally requires more overhead per investment.

Major stakeholders at venture funds include general partners (GPs), who work at the fund management company and execute investments, and limited partners (LPS), the institutions or wealthy individuals who invest in the funds. Most traditional funds are set to a fixed term of 10 years, so that LPs have certainty as to when capital calls will be made and when returns will be distributed. The 'vintage year' of these funds refers to the first close of the fund, the point at which money is committed by LPs and can be called upon by the GPs to make investments opportunities. Once the investments made by the general partners reach a certain rate of return for the LP investors (historically in the range of 8-12\%), a share of the fund's profits will be paid to the GPs (often up to $20 \%$ ). Separately, general partners are compensated and operating costs are paid through 'management fees' (typically an annual payment in the range of $1 \%$ to $2 \%$ of the committed capital of the fund). often used to describe money left in a fund for investments, but this term fails to distinguish between funds seeking new investments and those focused exclusively on supporting their existing portfolios (in which case dry powder is reserved for existing portfolio companies). For entrepreneurs seeking out a new investor, it is critical to know which VC funds are actively investing in new companies. As an example, the Sprout Group (last fund closed 2000) publicly stated its confinement only to follow-on investments, but this sort of public disclosure is a rarity. Let's call the capital available to make these new investments 'relevant powder', belonging to a subset of funds typically early in their life cycle.

Although the usual term of a VC fund lasts 10 years, the general investment strategy and activities of that fund change and mature over that period. Investments in new companies typically occur within the first 3 to 5 years after a fund's vintage year, and may account for $50 \%$ to $70 \%$ of the total fund assets (although this percentage may be decreasing as later-stage funding becomes less certain). In years 5 to 7 , meanwhile, funds typically focus on follow-on investments (investments to support existing portfolio companies) from the percentage of the fund 'reserved' for this purpose as well as on fundraising for new funds. In year 7 and onward, as funds approach the end of their intended life span, investment activity is usually limited as general partners (GPs) focus on fundraising, supporting existing portfolio companies, and/or deploying capital from new funds (Fig. 1). One can triangulate where a fund is in its life cycle by examining information on when it was raised, the investment history and word of mouth.

\section{Hard data}

We have compiled a database of $>200$ VC firms that invest (or have invested) in healthcare as a starting point for our analysis (Supplementary Table 1). Although some corporate-associated, strategic or other nontraditional funds are included in this table, the list generally focuses on traditional VC funds that have been recently active and that have US offices. We assembled hard data on $\mathrm{VC}$ fund activity from the VC funds themselves through public information, press reports and our own sources. Additional fund information can also be purchased through private databases (ThomsonOne (http://bit.ly/18xLIe1), Elsevier Business Intelligence (http://www.elsevierbi.com/) or similar). One can easily find general selfdescribed information on fund focus and strategy. Available data also usually include life cycle information, such as the last time a fund was closed (and its size), along with the dates of publicly made new investments. An attempt was made to contact each firm to ask for corrections to the information in this and Supplementary Table 1. In general, data were last updated on 1 September 2013.

How should you use these data? Let's say you are a US-based entrepreneur with a nascent seed- or early-stage biotech company (not a software or information technology (IT) company). We can assume that VC firms that have just raised a fund recently and/or have recently invested in a new company are likely to have relevant powder remaining. On the other hand, we can guess that those firms with older funds and no recent new investments will have limited relevant powder. In our prioritization, we view favorably funds that have raised new money in 2009 or later (although the newer, the better). We also select for firms which have made a new investment in 2012 or later.

To bias for firms with relevant powder, this hypothetical entrepreneur could apply the following filters to this database: specific public interest in life science, biotech or related sectors (not just 'health IT'); investment in seed, early, or all stages of companies; most recent fund vintage date 2009 or later; the existence of a US office; and a most recent new investment (not a follow-on investment in a current portfolio company) in 2012 or later. These filters result in the list of VC funds in Table $\mathbf{1}$. As an additional important filter, one could select VC funds with a publicly declared focus on whichever category or technology type more specifically describes the new company (see data in Supplementary Table 1). Even with these filters, the number of firms identified is likely to be large enough that additional prioritization will be desired.

As always, there are caveats. As mentioned in the introduction, this dataset and analysis are imperfect, and omitted funds may in fact be actively investing in new early-stage opportunities. One example is MVM (omitted from Table 1 due to a last fund closing 
in 2008), which has stated that it is actively seeking new opportunities and which made a new investment in 2013. In general, it takes substantial time for firms to raise new funds, and this process is kept behind closed doors. For example, Lightstone Ventures (formed mainly by ex-ATV and Morgenthaler personnel) is raising a new fund (http://reut. rs/Qu5Be8). Also, venture capitalists often attempt to keep the details of new investments confidential, as they seek to protect either the business models of innovative companies or the goals of their own venture funds.

\section{Final thoughts}

We think there is an opportunity to supplement these data on VC funds through a peer review process and by asking for feedback from people in the community. For example, the executive search firm the Coelyn Group surveyed a group of life science executives about whether venture capitalists were 'actively' seeking investments and then surveyed the VC firms to confirm or deny the results. This report inspired our original attempt to 'crowdsource' a database on VC funds (http://bit.ly/15KLHFm). As a first pass, we combined existing data into a living document and created an online survey for individuals to contribute to the data set. With a peer review process, it is important to ascertain the validity of new information or opinions and to ascertain any avoidable bias. Although opinions may be reported to the public anonymously, all are able to contribute and each opinion can be attributed to an original source. This open approach, in addition to the fact that we are making the entire data set publicly available, helps differentiate our work from other sources of information.

We would like to facilitate an ongoing dialogue about relevant powder through periodic blog postings, e-mail and Twitter (Box 4), providing updated information and opportunities for word of mouth feedback. This resource also can and should be used by venture firms to keep their information current.

For those seeking funding, objective data on relevant powder is certainly a helpful starting point, but our sample search illustrated in Table 1 still resulted in a list of more than 50 firms. Each entrepreneur must set their own fundraising strategy based on objective and subjective data, and entrepreneurs must perform their own due diligence to see if a fund is likely to be a good partner. You must understand the investing strategy of each VC firm you approach, as 'early-stage funding' has many definitions (from financing a university spinout with new target biology

Table 1 Recently active US noncorporate associated VC funds with stated interests not limited to health IT and/or IT

vC firm

5AM Venture Management

Aberdare Ventures

Abingworth Management Ltd

Arboretum Ventures

Ascent Biomedical Ventures

AshHill Pharmaceutical Investments

Atlas Venture

Avalon Ventures

Baird Capital

Bessemer Venture Partners

Burrill \& Company

Canaan Partners

Correlation Ventures

Domain Associates

Essex Woodlands Health Ventures

Fidelity Biosciences

Flagship Ventures

Foundation Medical Partners

Founders Fund

Frazier Healthcare Ventures

Gilde Healthcare Partners

Greenspring Associates

H.I.G. Bioventures

Helix Ventures

HLM Venture Partners

Index Ventures

Kleiner Perkins Caufield \& Byers

Longitude Capital Management Co.

Longwood Founders Management

Lux Capital

Maxwell Biotech Fund

Mitsui Ventures

MPM Capital

New Enterprise Associates, Inc. (NEA)

North Coast Technology Investors

Norwest Venture Partners

Okapi Venture Capital

ONSET Ventures

OrbiMed Advisors

Osage University Partners

Pappas Ventures

Polaris Partners

Prospect Venture Partners

Sante Ventures

Sofinnova Ventures Inc

Spring Mountain Capital

SV Life Sciences

Technology Partners

TEXO Ventures

Third Rock Ventures

Third Security

Tristar Technology Ventures

Vatera Healthcare Partners

venBio Partners

Venrock, Inc.

Venture Investors

Versant Ventures

Vivo Ventures
URL

http://5amventures.com/

http://www.aberdare.com/

http://www.abingworth.com/

http://www.arboretumvc.com/

http://www.abvlp.com/

http://www.ashhill.net/

http://www.atlasventure.com/

http://www.avalon-ventures.com/

http://www.bairdcapital.com/bairdcapital/venture-capital.aspx http://www.bvp.com/

http://venture.burrillandco.com/

http://www.canaan.com/

http://correlationvc.com/

http://domainvc.com/

https://www.ewhv.com/

http://www.fidelitybiosciences.com/

http://www.flagshipventures.com/

http://www.foundmed.com/

http://www.foundersfund.com/

http://www.frazierhealthcare.com/

http://www.gildehealthcare.com/

http://greenspringassociates.com/

http://www.higbio.com/

http://www.helixventure.com/

http://www.hlmvp.com/

http://www.indexventures.com/

http://www.kpcb.com/

http://www.longitudecapital.com/

http://www.longwoodfund.com/

http://www.luxcapital.com/

http://maxwellbiotech.com/

http://www.mitsui-global.com/en/

http://www.mpmcapital.com/

http://www.nea.com/

http://www.northcoastvc.com/

http://www.nvp.com/

http://okapivc.com/

http://www.onset.com/

http://www.orbimed.com/

http://osagepartners.com/osage-university-partners/

http://www. pappasventures.com/

http://www.polarispartners.com/

http://www. prospectventures.com/

http://santeventures.com/

http://www.sofinnova.com/

http://www.springmountaincapital.com/

http://www.svlsa.com/

http://www.technologypartners.com/

http://texoventures.com/

http://www.thirdrockventures.com/

http://www.thirdsecurity.com/

http://tstventures.com/

http://www.vaterahealthcare.com/login.php

http://www.venbio.com/

http://www.venrock.com/

http://www.ventureinvestors.com/

http://www.versantventures.com/

http://www.vivoventures.com/

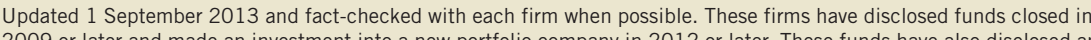
2009 or later and made an investment into a new portfolio company in 2012 or later. These funds have also disclosed an interest in seed, early or all stages of investments in life sciences or biotech related fields (not just health IT). Funds missing from this list may still be actively making new investments. 


\section{Box 3 Points to consider when approaching nontraditional corporate VCs}

Also worthy of investigation are nontraditional funds, including open-ended evergreen funds and corporate-associated venture funds (some of which are included in Supplementary Table 1). Corporate associated venture funds, in particular, have become an increasingly important part of the life sciences start-up ecosystem, especially for early-stage investments. As biotech and pharma companies seek novel ways to access external innovation, corporate venture funds often serve as a vehicle charged with seeking both strategically and/ or financially attractive opportunities.

For entrepreneurs, it is important when fundraising to consider the strategic and structural attributes that set corporate venture funds apart from traditional venture funds. To begin with, for corporate funds with a mandate that includes strategic relevance, it is critical to understand the level of overlap between your focus areas and those of the fund. Also important is your fit within other elements of the fund mandate, including your stage of development (are your assets preclinical or do you have clinical data?) and technology modality (for example, small-molecule therapeutics versus biologics, therapeutics versus diagnostics). Financial autonomy is another important factor: autonomous corporate funds may operate with a separate budget that isn't subject to internal review or, in some cases, with a closed fund structure similar to those of traditional funds. Less autonomous corporate funds, meanwhile, may have no separate budget allocation and a more arduous internal review process. In any case, the analysis presented above regarding fund life cycles and dry powder usually do not apply to nontraditional venture capital funds.

Entrepreneurs should also carefully consider whether funding from corporate partners comes with any specific benefits or drawbacks that extend beyond the near-term capital invested. In some cases, for example, corporate venture funds may provide start-ups with strategic benefits in the form of resources and know-how related to technology development, clinical development, marketing and beyond. These investments may come with, or improve the likelihood of, strategic partnerships or future acquisitions. On the flip side, there are cases where corporate investments are linked to strategic or financial terms affecting future upside, such as option rights (for example, where the investor has the option to acquire rights to an asset for a prenegotiated price after a certain milestone is met). and minimal preclinical validation data to financing an asset that has human efficacy data associated with it), and fewer VC firms are now focusing on investments straight out of academia. There has been a recent exodus from early-stage life science VC, with many firms either changing their risk tolerances, not raising new funds to invest (for example, CMEA, Column Group, Prospect Ventures, Skyline), or reducing their life sciences activity or investing staff (for example, ATV, Highland Capital, Morgenthaler, Scale, Versant Ventures).

In addition, a list is just a starting point. Many conversations leading to investments are prompted by serendipitous introductions and personal relationships (and not necessarily by finding the 'best fit'). Once you identify firms that seem a fit for your enterprise, try to find someone in your network (or someone you can contact) who can approach the VC firm on your behalf and provide an introduction. Do your diligence and see if partners in the fund have described their current desires for new investments, perhaps on their own blogs or through social media. Historically, it has always been possible to find individuals at funds who made exceptions to the funds' gen-

\section{Box 4 Feedback}

For comments on the dataset, please reach the authors via email at (info@ puretechventures.com), or via Twitter at @PureTechH. We will incorporate feedback into new versions of the dataset and publish it periodically on our blog (http://www.puretechhealth.com/blog) and also through Nature Biotechnology's blog, Trade Secrets (http://blogs. nature.com/ tradesecrets/). Updates will be publicized via Twitter from both parties. eral rules for great investment opportunities. Furthermore, each venture fund may behave differently, including some that employ nontraditional models or have nontraditional limited partners to which generalities may not apply. Though this is an incomplete view of a changing landscape, we hope to aid entrepreneurs as they look to estimate firms' appetite and capability for new investment.

Note: Any Supplementary Information and Source Data files are available in the online version of the paper (doi:10.1038/nbt.2729).

\section{ACKNOWLEDGMENTS}

We would like to acknowledge Marco Mena, Megan Musacchio and Frank Zhu, who each provided critical research and analysis.

\section{COMPETING FINANCIAL INTERESTS}

The authors declare competing financial interests: details are available in the online version of the paper (doi:10.1038/nbt.2729).

Corrected after print 26 November 2013 
CFI declaration:

The authors are employed by PureTech Ventures (J.B. and P.M.) and Enlight Biosciences (J.B.). 


\section{Corrigendum: In search of dry powder}

Jonathan Behr \& Phil Murray

Nat. Biotechnol. 31, 961-964 (2013); doi:10.1038/nbt.2729; published online 31 October 2013; corrected after print 26 November 2013

In the version of this article initially published, the Twitter contact was listed as @PureTechV. The correct contact is @PureTechH. The error has been corrected in the HTML and PDF versions of the article. 